\title{
Influence of Semisolid Squeeze Casting Technology on Alpha Phase and Eu- tectic of AlSi7Mg0.3
}

Richard Pastircak, Denis Martinec, Elena Kantorikova

Department of Technological Engineering, Faculty of Mechanical Engineering, University of Žilina. Univerzitná 8215/1, 01026 Žilina. Slovak Republic. E-mail: denis.martinec@fstroj.uniza.sk, richard.pastircak@fstroj.uniza.sk

The paper deals with processing of material in semisolid state by the technology of semisolid squeeze casting. The investigated material was a subeutectic aluminium alloy AlSi7Mg0.3. The influence of various preparation methods of batch material on the structure after processing by this technology was studied. Alloy AlSi7Mg0.3 was prepared as gravity cast, inoculated, heat treated and by technology of direct squeeze casting. In article is assessed microstructure of castings before and after processing by technology of semisolid squeeze casting. The shape and distribution of eutectic silicon was observed. The shape and the distribution of alpha phase formations has an impact on whether micro-volumes of molten eutectic will be closed in alpha phase or will be segregated along the boundaries of alpha phase formations. It was observed the partial inheritance in microstructure. Also the segregation in surface layer was observed.

Keywords: Squeeze Casting, Al-Si Alloys, Semisolid, Crystalization under pressure

\section{Introduction}

Semisolid metal processing (SSM) is one of the casting methods, in which a partially solidified metal slurry is injected into a mold cavity. The partially solidified metal slurry consists typically of $50 \%$ liquid and $50 \%$ solid. Technology of semisolid squeeze casting (SSSC) combines semisolid forming and squeeze casting to improve the conventional squeeze casting method (SC). This technology was summarized by Ghomashchi and Vikhrov. [1-7]

There are some major advantages in the semisolid metal processing. Some of them are:

- Extending mould life. The metal slurry contains about $50 \%$ of the solid phase during casting, which means that a considerable amount of heat from the phase conversion has been released before injection into the mould cavity, thereby significantly reducing its thermal load.

- Reducing the time required for one casting cycle, since by reducing the energy released during solidification, the setting time is reduced by almost half.

- Reducing the impact of the shrinkage process.

- Increasing casting integrity and improving properties.

The influence of squeeze casting technology on microstructure and mechanical properties of aluminium and magnesium alloys has been extensively investigated in several works. During semisolid processing is the uniform distribution of primary particles in the matrix a critical parameter to reach desired properties of cast. Segregation in semisolid materials leads to heterogeneous properties. This effect is result of different flow behaviours of the liquid phase and solid globules. Vieira and Ferrante studied the segregation susceptibility of aluminium-silicon alloys in semi-solid state. They found that the segregation behaviour was correlated to microstructure. They also realised that segregation occurred during rising up of the semi-solid material through the space between the die and the plunger. Based on the changes, Vieira and Ferrante defined three different regions in the microstructure: a densified region, a semisolid region and a liquid phase region. They also defined that the higher impact on the segregation has the shape of cast than the velocity of flow. [8-15]

The aim of this paper is to observe inheritance between initial material microstructure and microstructure of the cast after SSSC processing. Also the segregation process was observed.

\section{Experimental material and process}

As experimental material was used the AlSi7Mg0.3 alloy because its mechanical and casting properties, option of heat treatment and wide solidification range. Chemical composition of this alloy is shown in table 1. 
Tab. 1 Chemical composition of the used AlSi7MgO.3 alloy $[w t . \%]$

\begin{tabular}{|c|c|c|c|c|c|}
\hline $\mathbf{S i}$ & $\mathbf{M g}$ & $\mathbf{F e}$ & $\mathbf{M n}$ & $\mathbf{T i}$ & $\mathbf{A l}$ \\
\hline 7.01 & 0.31 & 0.19 & 0.02 & 0.12 & Bal. \\
\hline
\end{tabular}

From the alloy were created samples by the technology of gravity die casting into metal mold. A part of the samples were inoculated with 0.2 wt. $\%$ of AlTi5B1. For observing the influence of the eutectic morphology were a part of the samples heat treated by the dissolution annealing. Annealing temperature was $540{ }^{\circ} \mathrm{C}$, time 6 hours, cooling to water with $60^{\circ} \mathrm{C}$. In addition to the gravity casted samples, were created samples by technology of direct squeeze casting. Temperature of casting was $700{ }^{\circ} \mathrm{C}$, temperature of the mold $250^{\circ} \mathrm{C}$, pressure $100 \mathrm{MPa}$. Thus prepared samples were machined into desired dimensions.
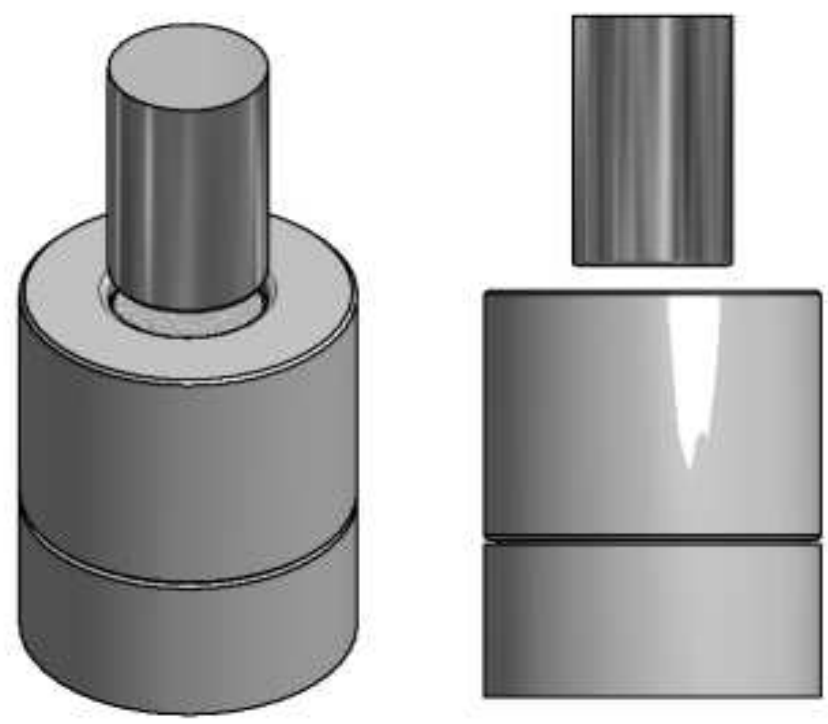

Initial material with different methods of preparation was processing by the technology of SSSC. Sketch of the experimental measurement is described on figure 1 . The surface of the die cavity and the surface of the samples themselves was treated with a graphite coating. The semisolid state of the samples was achieved by heating them to a temperature with $50 \%$ of liquid phase. The heating was carried out by placing the samples in steel jigs in a resistance chamber furnace, which had been preheated to a required temperature. The heating of the samples was monitored using K-type thermocouples located in the control sample. After reaching the desired temperature, the specimens were individually extruded on a conventional hydraulic press into circular cross-section mould. The pressure applied to the sample was $100 \mathrm{MPa}$. Temperature of the mold and piston was $200 \pm 5^{\circ} \mathrm{C}$.

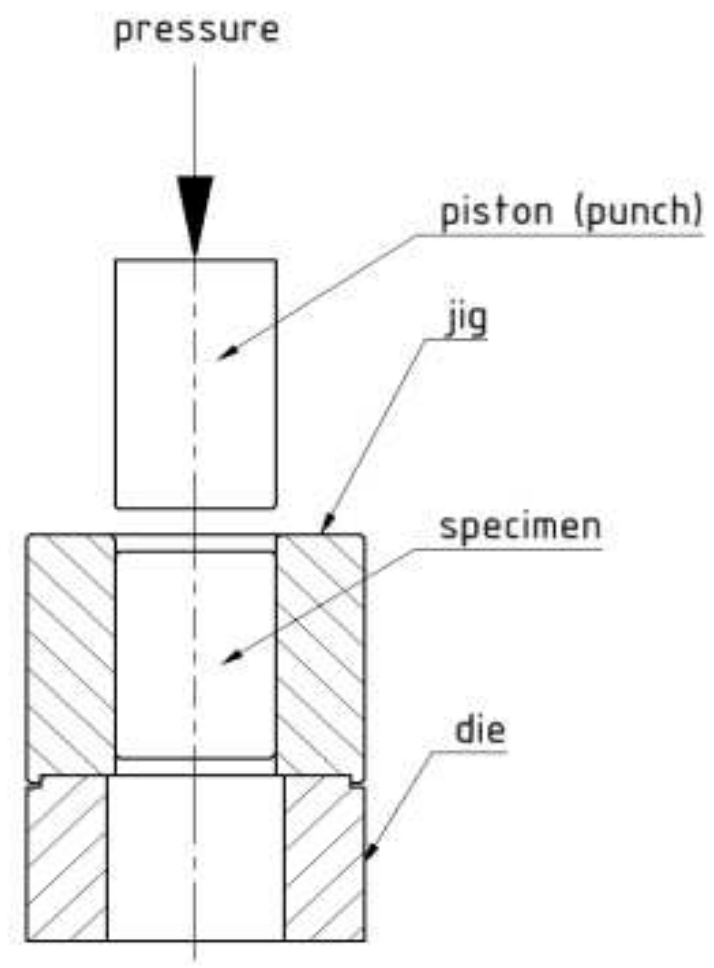

Fig. 1 Parts of experimental mold
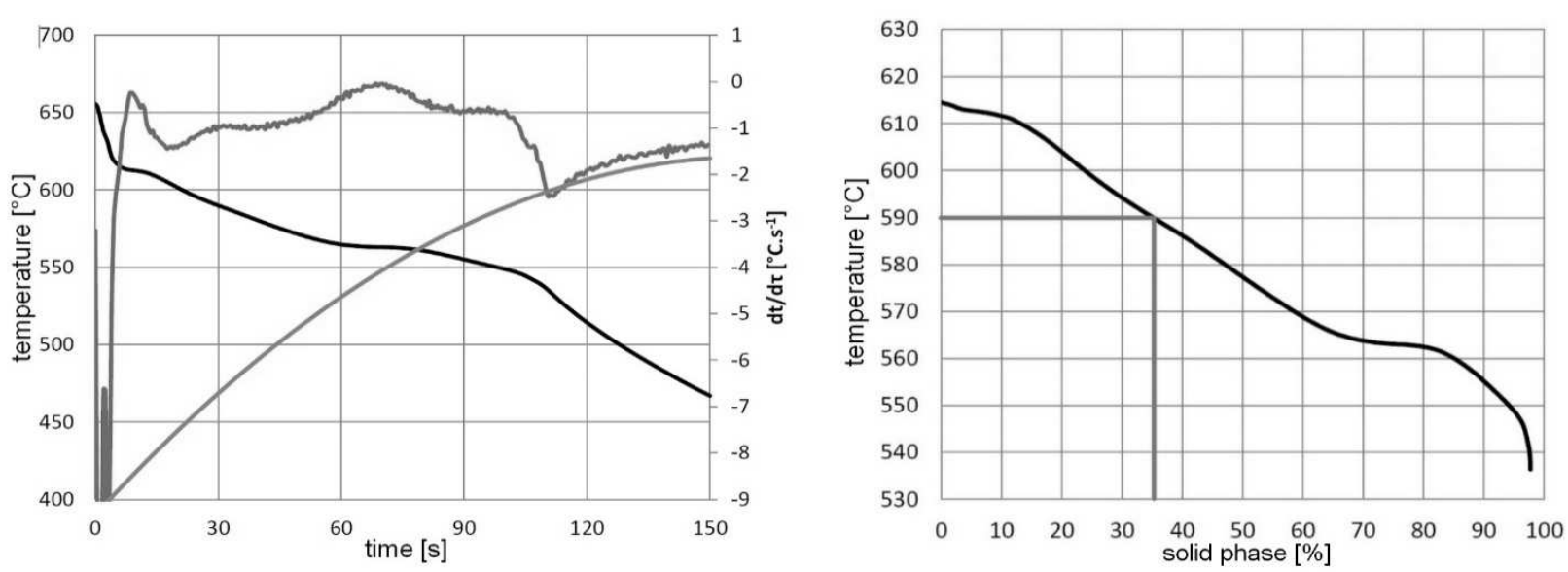

Fig. 2. Thermal analysis of AlSi7MgO.3 
Heating temperature of casting material was set to level with 50\% liquid phase and 50\% solid, i. e. $578 \pm 1^{\circ} \mathrm{C}$. Temperature with $50 \%$ of liquid phase was defined by the thermic analysis of used alloy (fig. 2).

\section{Results}

On figure 3 are shown microstructures of samples in its initial level. These pictures were taken at $50 \mathrm{x}$ magnification.

The microstructure of AlSi7Mg0.3 alloy is composed of an alpha aluminium phase and eutectic silicon in lamellar form (fig. 3a). Due to the inoculating, the

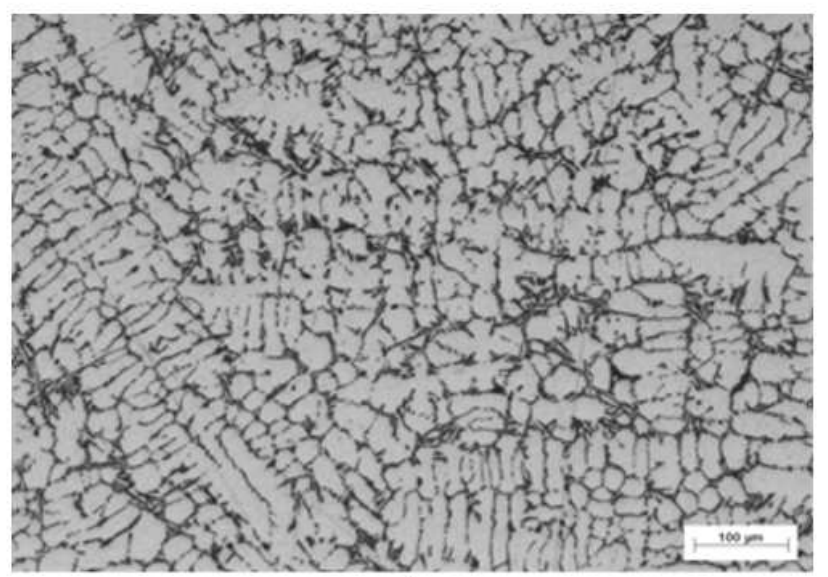

a)

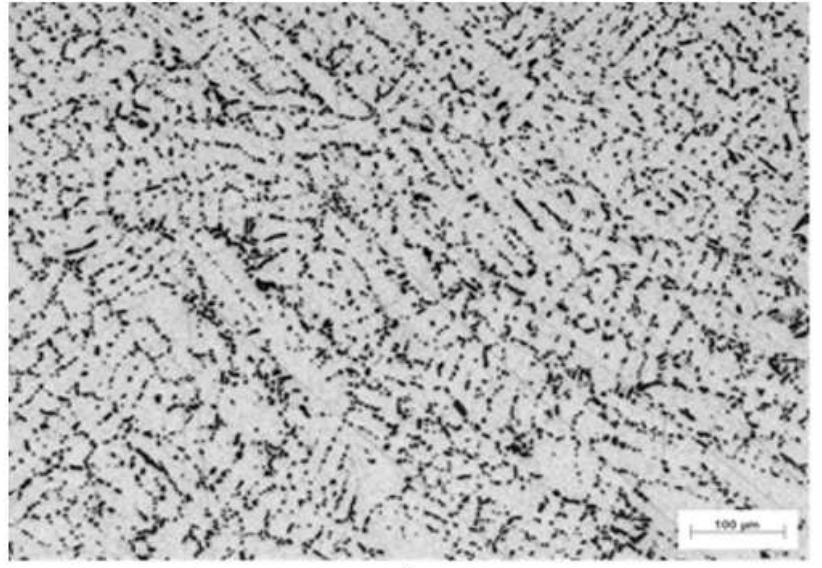

c) microstructure (fig. 3b) was refined and primary dendritic arms of alpha phase were shortened. Eutectic silicon is segregated in interdendritic spaces in lamellar form as in non-inoculated alloy. After heat treatment, the microstructure consists of alpha phase dendrites with the size as in unaffected alloy. Eutectic silicon is segregated in globular form (fig. 3c). In material prepared by squeeze casting technology, the microstructure consists of fine alpha phase dendrites with short secondary arms. Eutectic silicon is segregated in the form of lamellae which are shorter than in unaffected alloy (fig. 3d).

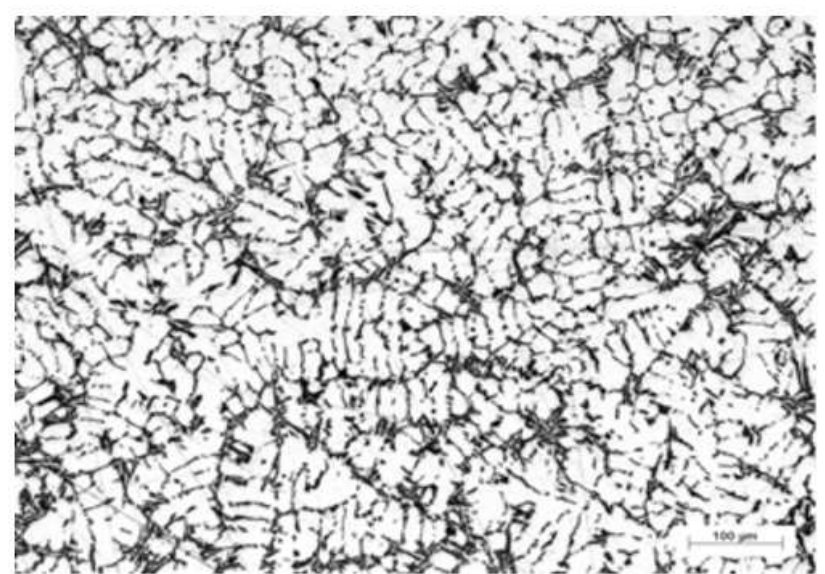

b)

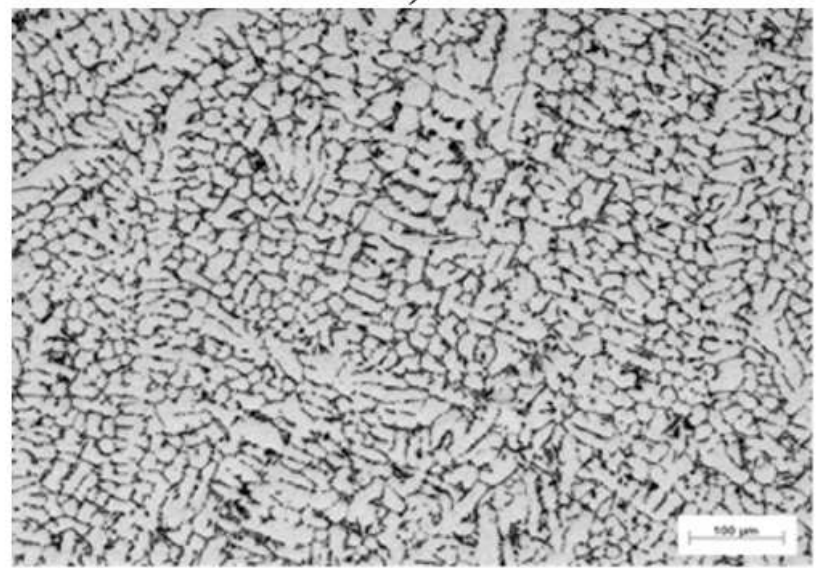

d)

Fig. 3 Microstructure of initial material a) gravity cast, b) inoculated alloy, c) beat treated alloy, d) alloy casted by technology of direct SC

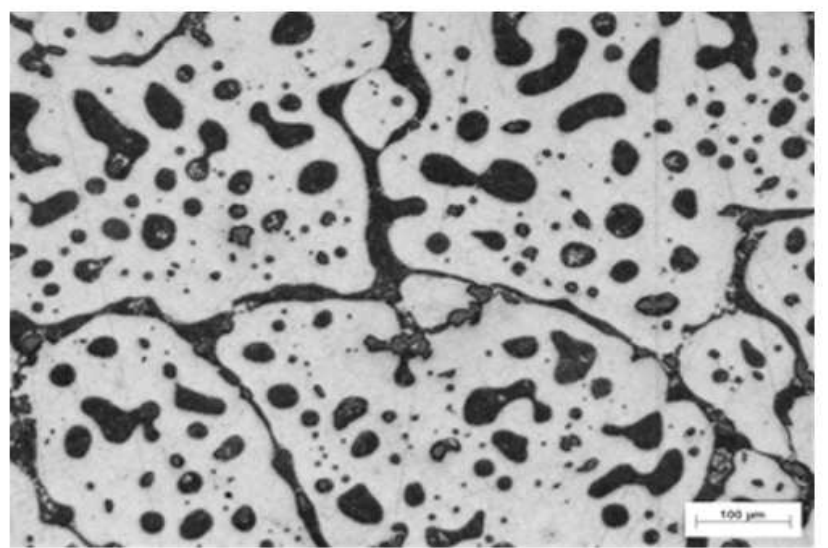

a)

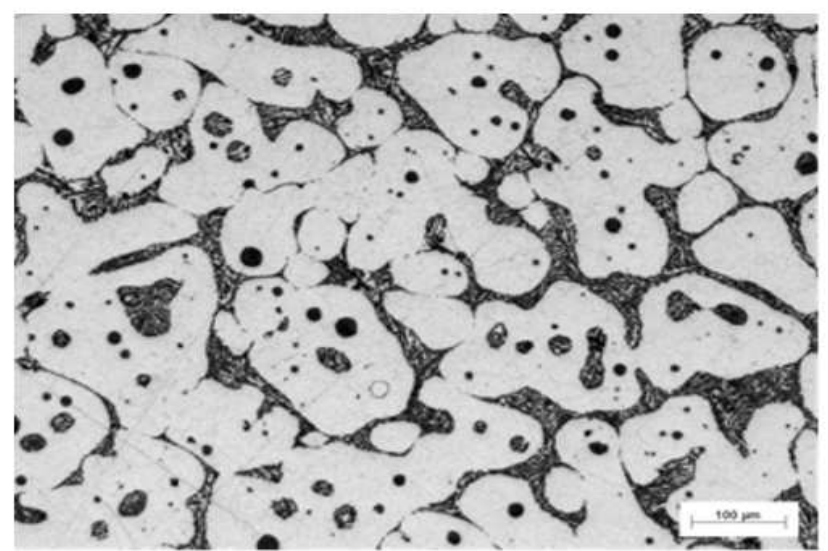

b) 


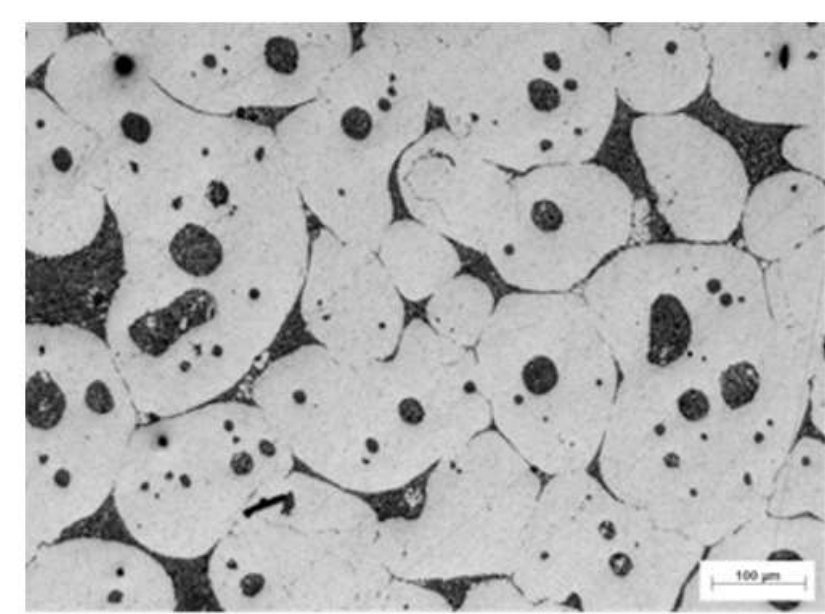

c)

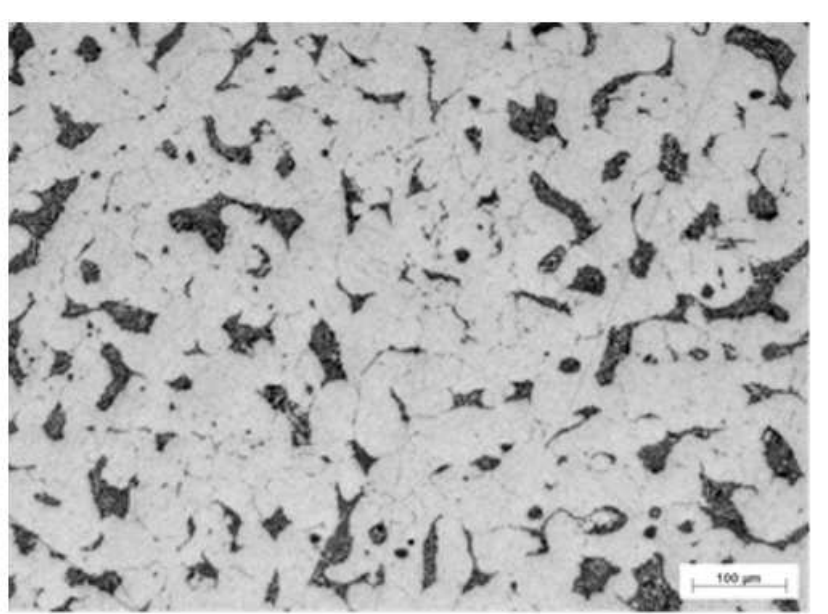

d)

Fig. 4 Microstructure of samples after SSSC a) gravity cast, b) inoculated alloy, c) heat treated alloy, d) alloy casted by direct SC.

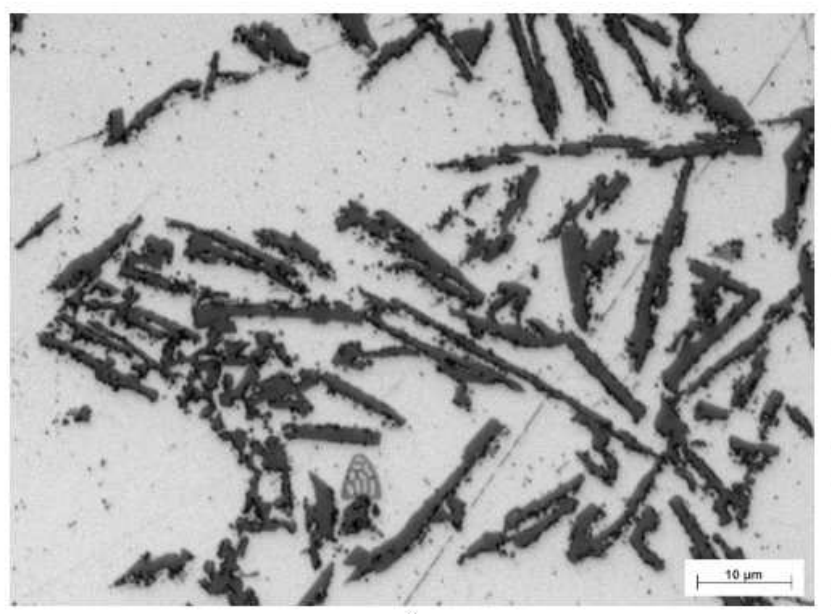

a)

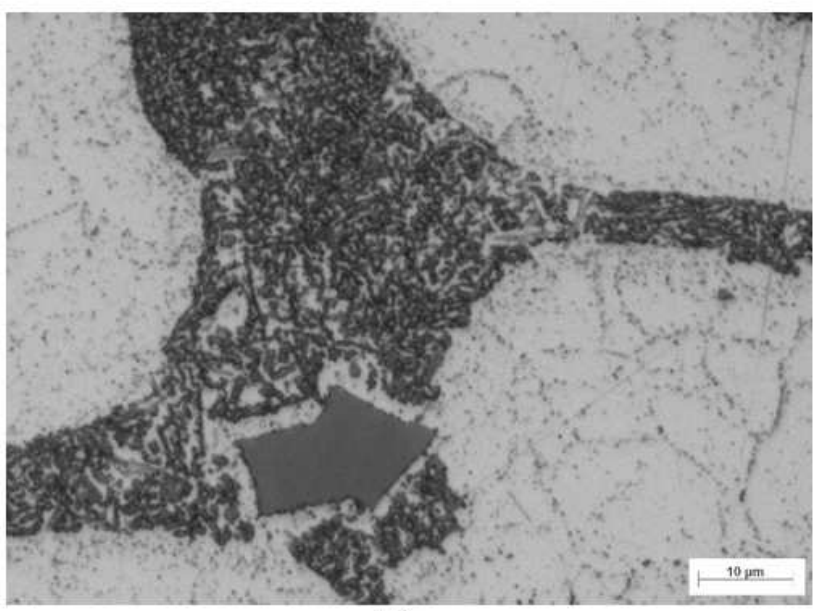

b)

Fig. 5 Microstructure of AlSi7MgO.3 alloy a) gravity cast, b) after SSSC

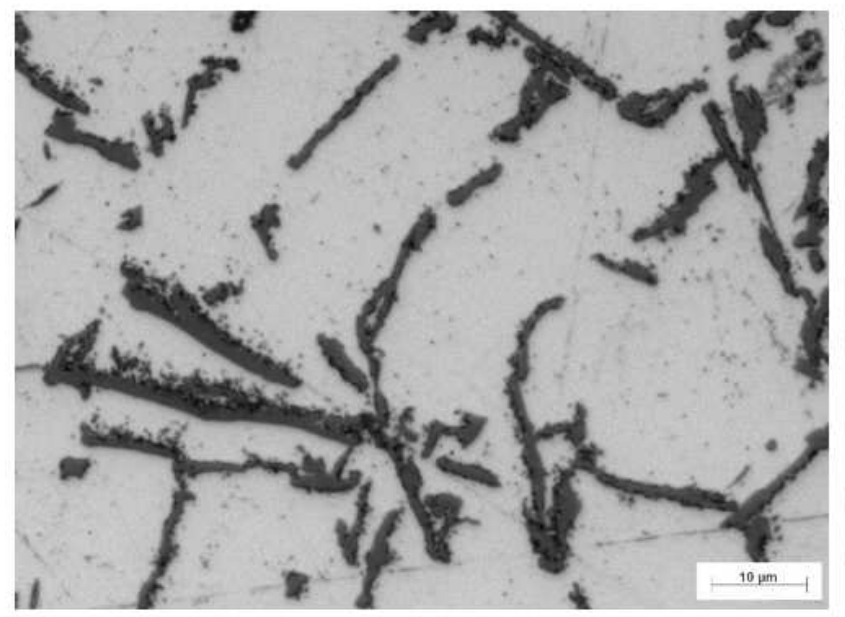

a)

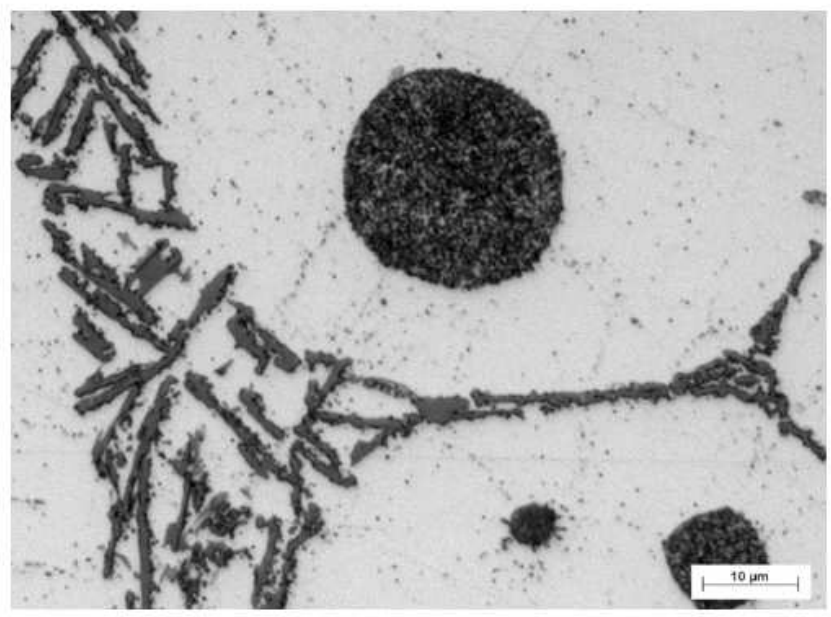

b)

Fig. 6 Microstructure of ALSi7MgO.3 alloy a) after inoculation, b) SSSC of inoculated alloy 


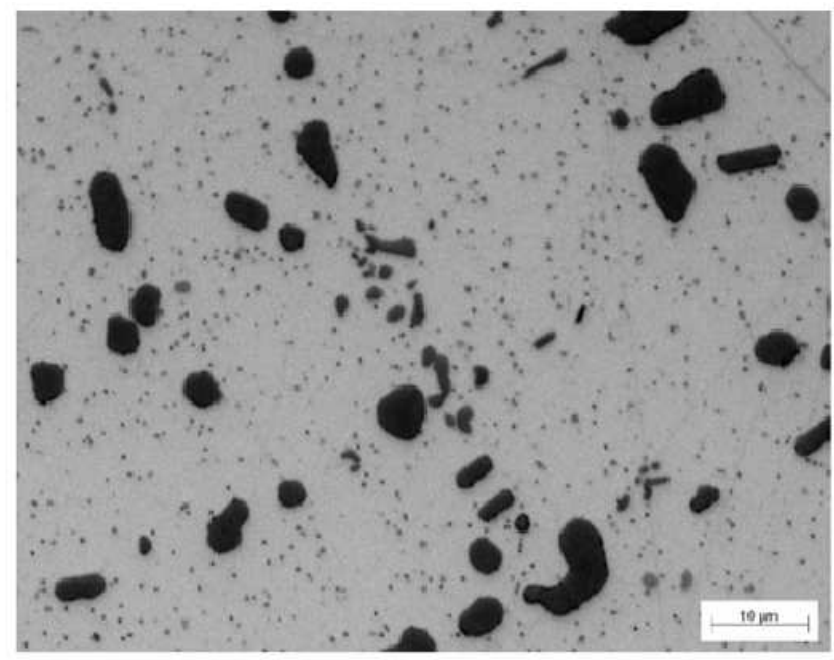

a)

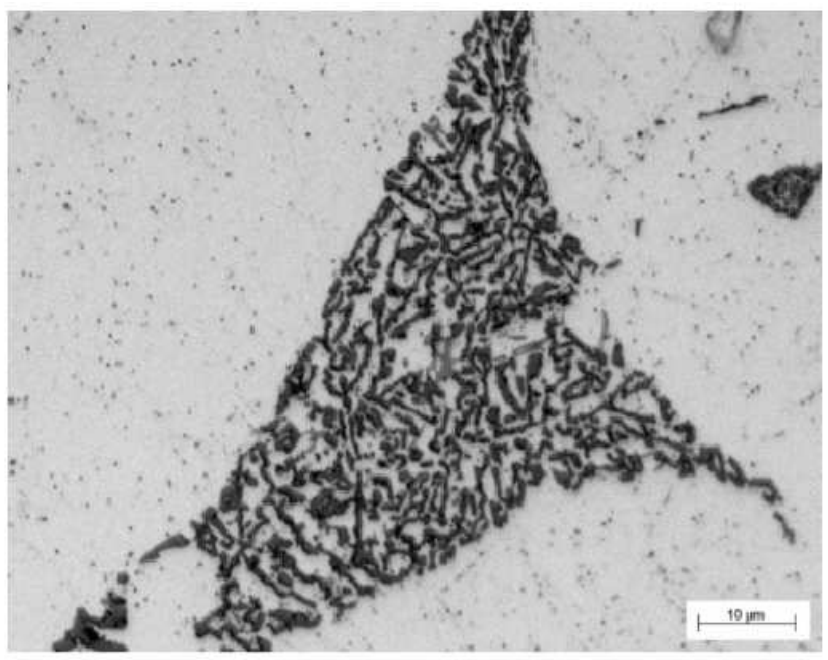

b)

Fig. 7 Microstructure of heat treated alloy a) after heat treatment b) after heat treatment and SSSC

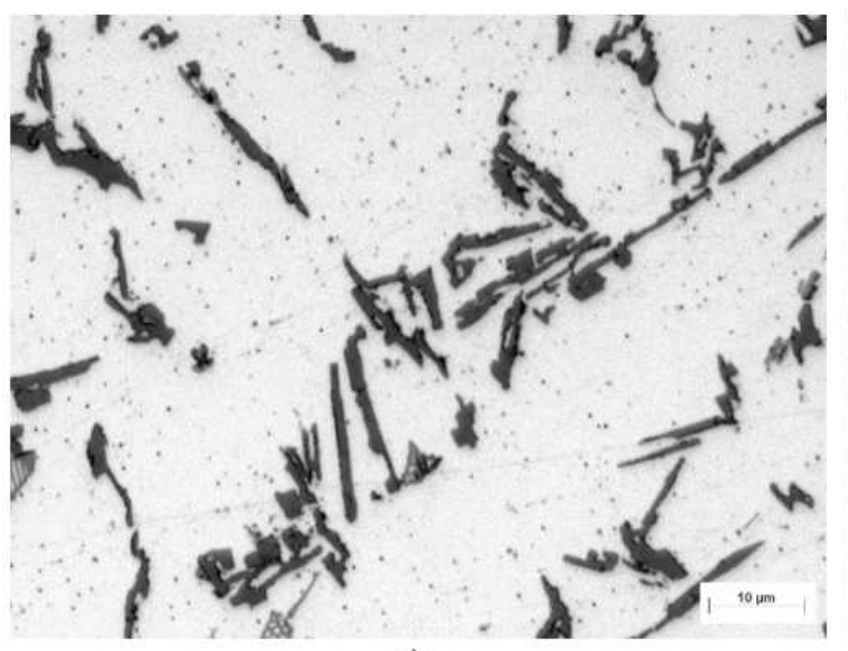

a)

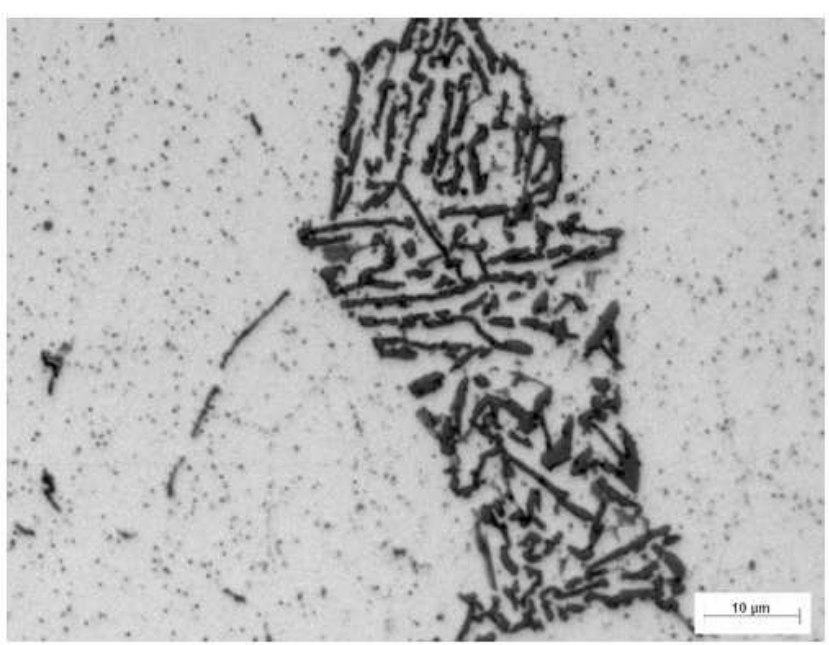

b)

Fig. $\boldsymbol{8}$ Microstructure of alloy a) casted by direct SC b) prepared by direct SC and processed by SSSC

After processing by technology of semisolid squeeze casting, changes in the microstructures relative to the initial state of material can be observed on the pictures. Microstructure of alloy unaffected before SSSC consists of the alpha phase in large globular formations (fig. 4a). Along the boundaries of these formations is segregated eutectic silicon in the form of fin fibrous. Due to the higher solidification pressure, the content of silicon in eutectic is increased. The higher silicon content has made it possible to observe compact silicon particles of 10 to $20 \mu \mathrm{m}$ in the microstructure (fig. 5b). The molten eutectic, which was not segregated along the boundaries remained trapped in the formations of alpha phase and solidified in a globular form (fig. 4a). In the inoculated alloy, both the alpha phase and eutectic silicon are similar to the unaffected alloy. In SSSC structure can be observed inheritance of structure after inoculation. The alpha phase formations are significantly smaller (fig. 4b). The trapped eutectic silicon is also segregated in globular form with finer distribution as in the previous case (fig 6). The bulk of the eutectic silicon has been segregated along the boundaries of the globular alpha phase formations. Changes in the structure affected by heat treatment and SSSC are similar to those of the inoculated alloy (fig. 4c). Eutectic silicon, which was segregated in globular form (fig. 7a), changed to fine rods after SSSC (fig. 7b). The structure that solidified under pressure is characterized by an increase of the silicon proportion in eutectic and alpha phase in globular form. Re-application of solidification pressure resulted in formation of smaller alpha phase globules than in the previous cases (fig. 4d). After subsequent processing by SSSC technology the eutectic silicon didn't trap among alpha phase dendrites, because the conditions for the flow of molten eutectic was significantly more favourable. The eutectic is thus segregated in form of rods along the boundaries of alpha phase formations (fig. 8). 


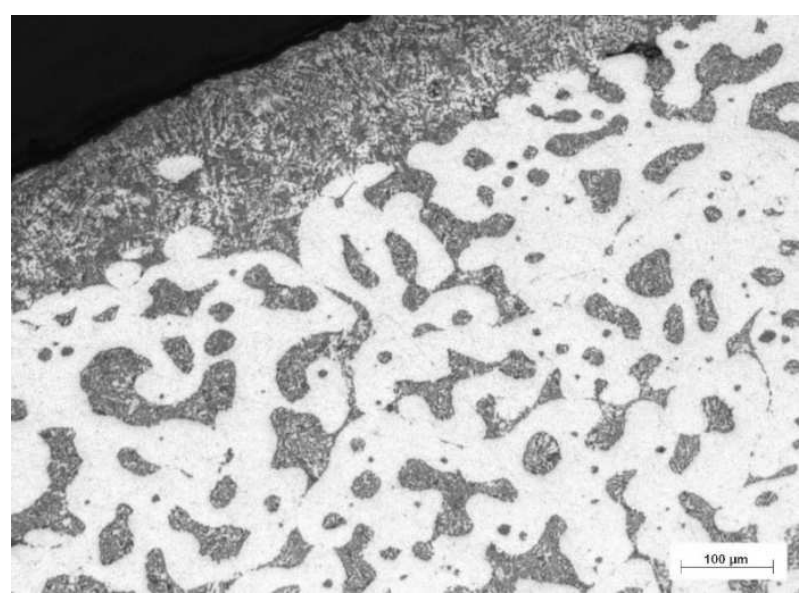

Fig. 9 Segregation in surface layer

In addition to the above, segregation of the eutectic in the surface layer was observed on all samples (fig. 9). The thickness of this layer ranged from 50 to $200 \mu \mathrm{m}$. This segregation was occurred by forcing the molten eutectic through a network of dendrites to the surface of the mold cavity.

\section{Conclusions}

Based on the results, it can be concluded that the semisolid processing partially preserves the initial structures of the material. Inheritance of the structure show itself in the inoculated alloy by finer distribution of the alpha phase. The fine globular structure of the material prepared by squeeze casting has the effect of different eutectic silicon segregation, only along the boundaries of alpha phase formations. The shape and the distribution of alpha phase formations has an impact on whether micro-volumes of molten eutectic will be closed in alpha phase or will be segregated along the boundaries of alpha phase formations. Segregation processes in the observed samples were observed only in the surface layer. The surface layer of the cast was formed only by the eutectic.

\section{Acknowledgment}

This study has been supported by the Scientific Grant Agency of the Ministry of Education of the Slovak Republic VEGA 1/0494/17. The authors acknowledge the grant agency for support.

\section{References}

[1] FLEMINGS, M C. (1991). Behavior of metal alloy in the semi-solid state, J. Metall Trans A, 22(5), 957-981.

[2] FAN, Z. (2002). Int.Mater.Rev. 47(2), 1-39.

[3] LUO, S.J., KEUNG, W.C., KANG, Y.L. (2010). Trans. Nonferrous Met. Soc. China20, 1805-1814.

[4] DAO, V.L., ZHAO, S.D., LIN, W.J. (2011) Spec.Cast. Nonferrous Alloys 31(8), 687-690.

[5] RICHTÁRECH, L., BOLIBRUCHOVÁ, D., BRUंNA, M. (2015). Archives of Foundry Engineering 15(2), 95-98.

[6] PAN, Q.Y., APELIAN, D., JORSTAD, J. (2008). Semisolid Casting-Introduction and Fundamentals. ASM Handbook, Volume 15: Casting, 761-763.

[7] GHOMASHCHI M.R., VIKHROV, A. (2000). J. Mater. Process. Technol. 101, 1-9.

[8] KONAR, R., MICIAN, M. (2017) Archives of foundry engineering. 17 (2), 35-38. DOI: 10.1515/afe-2017-0047

[9] BRŮNA, M., SLÁDEK, A., KUCHARČÍK, L. (2012). Archives of Foundry Engineering 12(1), 5-8.

[10] VIEIRA, E.A.; KLIAUGA, A.M.; FERRANTE, M. SCR. MATER. 2007, 57, 1165-1168.

[11] MALEKI, A., SHAFYEI, A., NIROUMAND, B. (2009) J. Mater. Process. Technol. 209, 37903797.

[12] MALEKI, A., NIROUMAND, B., SHAFYEI, A. (2006). Mater. Sci. Eng. A 428, 135-140.

[13] MOSOUMI, M., HU, H. (2011) Mater. Sci. Eng. A 528, 3589-3593.

[14] SKOLIANOS, S.M., KIOURTSIDIS, G., XATZIFOTIOU, T. (1997). Mater. Sci. Eng. A 231, 17-24.

[15] LEE, J.H., KIM, H.S., WON, C.W., et al. (2002). Mater. Sci. Eng. A 338, 182-19.0 